\title{
Sensitivity of gas-grain chemical models to surface reaction barriers
}

\section{Effect from a key carbon-insertion reaction, $\mathrm{C}+\mathrm{H}_{2} \rightarrow \mathrm{CH}_{2}$}

\author{
M. Simončič ${ }^{1}$, D. Semenov ${ }^{2,3}$, S. Krasnokutski ${ }^{4}$, Th. Henning ${ }^{2}$, and C. Jäger ${ }^{4}$ \\ ${ }^{1}$ Faculty of Chemistry and Chemical Technology, University of Ljubljana, Večna pot 113, 1000 Ljubljana, Slovenia \\ e-mail: matjaz.simoncic@fkkt.uni-lj.si \\ ${ }^{2}$ Max-Planck-Institut für Astronomie, Königstuhl 17, 69117 Heidelberg, Germany \\ e-mail: semenov@mpia.de \\ 3 Department of Chemistry, Ludwig Maximilian University, Butenandtstr. 5-13, 81377 Munich, Germany \\ ${ }^{4}$ Laboratory Astrophysics and Cluster Physics Group of the Max Planck Institute for Astronomy at the Friedrich Schiller University \\ Jena, Institute for Solid State Physics, Helmholtzweg 3, 07743 Jena, Germany
}

Received 3 February 2020 / Accepted 20 March 2020

\begin{abstract}
Context. The feasibility of contemporary gas-grain astrochemical models depends on the availability of accurate kinetics data, in particular, for surface processes.

Aims. We study the sensitivity of gas-grain chemical models to the energy barrier $E_{\mathrm{a}}$ of the important surface reaction between some of the most abundant species: $\mathrm{C}$ and $\mathrm{H}_{2}$ (surface $\mathrm{C}+$ surface $\mathrm{H}_{2} \rightarrow$ surface $\mathrm{CH}_{2}$ ).

Methods. We used the gas-grain code ALCHEMIC to model the time-dependent chemical evolution over a $2 \mathrm{D}$ grid of densities $\left(n_{\mathrm{H}} \in 10^{3}, 10^{12} \mathrm{~cm}^{-3}\right)$ and temperatures $(T \in 10,300 \mathrm{~K})$, assuming UV-dark $\left(A_{\mathrm{V}}=20 \mathrm{mag}\right)$ and partly UV-irradiated $\left(A_{\mathrm{V}}=3 \mathrm{mag}\right)$ conditions that are typical of the dense interstellar medium. We considered two values for the energy barrier of the surface reaction, $E_{\mathrm{a}}=2500 \mathrm{~K}$ (as originally implemented in the networks) and $E_{\mathrm{a}}=0 \mathrm{~K}$ (as measured in the laboratory and computed by quantum chemistry simulations).

Results. We find that if the $\mathrm{C}+\mathrm{H}_{2} \rightarrow \mathrm{CH}_{2}$ surface reaction is barrierless, a more rapid conversion of the surface carbon atoms into methane ice occurs. Overproduction of the $\mathrm{CH}_{n}$ hydrocarbon ices affects the surface formation of more complex hydrocarbons, cyanides and nitriles, and CS-bearing species at low temperatures $\$ 10-15 \mathrm{~K}$. The surface hydrogenation of CO and hence the synthesis of complex (organic) molecules become affected as well. As a result, important species whose abundances may change by more than a factor of two at $1 \mathrm{Myr}$ include atomic carbon, small mono-carbonic $\left(\mathrm{C}_{1}\right)$ and di-carbonic $\left(\mathrm{C}_{2}\right)$ hydrocarbons, $\mathrm{CO}_{2}, \mathrm{CN}, \mathrm{HCN}, \mathrm{HNC}$, $\mathrm{HNCO}, \mathrm{CS}, \mathrm{H}_{2} \mathrm{CO}, \mathrm{H}_{2} \mathrm{CS}, \mathrm{CH}_{2} \mathrm{CO}$, and $\mathrm{CH}_{3} \mathrm{OH}$ (in either gas and/or ice). The abundances of key species, $\mathrm{CO}, \mathrm{H}_{2} \mathrm{O}$, and $\mathrm{N}_{2}$ as well as $\mathrm{O}, \mathrm{HCO}^{+}, \mathrm{N}_{2} \mathrm{H}^{+}, \mathrm{NH}_{3}, \mathrm{NO}$, and most of the S-bearing molecules, remain almost unaffected.

Conclusions. Further accurate laboratory measurements and quantum chemical calculations of the surface reaction barriers will be crucial to improve the accuracy of astrochemical models.
\end{abstract}

Key words. astrochemistry - molecular processes - ISM: abundances - ISM: molecules

\section{Introduction}

To date, more than 200 interstellar molecular species have been discovered ${ }^{1}$ (McGuire 2018). These molecules include terrestrial-like stable molecules, more exotic unstable radicals, ions, complex species, macromolecules, and various ices. Among these complex species, a variety of complex organic molecules such as $\mathrm{CH}_{3} \mathrm{OH}, \mathrm{CH}_{3} \mathrm{CN}, \mathrm{HCOOCH}_{3}, \mathrm{CH}_{3} \mathrm{CHO}$, and $\mathrm{CH}_{3} \mathrm{OCH}_{3}$ have been found in the interstellar medium (ISM).

According to our current understanding of the chemical processes in space, molecules can be produced and destroyed through gas-phase and/or dust grain surface chemistry, with high-energy radiation and cosmic rays playing an important role (Cuppen et al. 2017). For example, CO, CS, carbon chains, and cyanopolyynes are mainly formed through ion-molecule and dissociative recombination reactions in the gas phase. In contrast, some simple key molecules such as $\mathrm{H}_{2}, \mathrm{NH}_{3}, \mathrm{H}_{2} \mathrm{O}, \mathrm{CH}_{4}$, and most of the complex organics are mainly synthesized through

1 https://cdms.astro.uni-koeln.de/classic/cologne_data surface processes (Hollenbach \& Salpeter 1971; Herbst \& van Dishoeck 2009; Tielens 2010). Among these processes, surface recombination of highly mobile atomic hydrogen with other species such as CO plays a very important role in building the molecular complexity of ice mantles. Similar reactions involving molecular hydrogen are usually considered to be of less importance because of substantial energy barriers. Modern public astrochemical databases such as $\mathrm{KIDA}^{2}$ and $\mathrm{UDFA}^{3}$ include thousands of low-temperature reactions that can occur under the ISM conditions. These reaction networks are used in various astrochemical models that simulate the chemical evolution of the ISM clouds, protoplanetary disks, circumstellar shells, and exoplanetary atmospheres (Herbst \& Yates 2013; Agúndez \& Wakelam 2013; Henning \& Semenov 2013; Rimmer \& Helling 2016).

Recently, a high reactivity of single carbon atoms toward different molecules has been demonstrated (Chastaing et al. 2000,

\footnotetext{
http://kida.obs.u-bordeaux1.fr

3 http://udfa.net
} 
2001; Kaiser \& Mebel 2002; Kaiser et al. 1999; Krasnokutski et al. 2017a; Shannon et al. 2014). In particular, efficient barrierless reactions of $\mathrm{C}$ atoms toward saturated closed-shell molecules have been identified. The high reactivity of carbon atoms persists over a broad temperature range starting from temperatures slightly above absolute zero. The reactions of carbon atoms with small molecules in the gas phase can lead to their efficient destruction (Krasnokutski et al. 2017a; Shannon et al. 2014). At the same time, for large molecules or $C$ atoms reacting on dust surfaces, such reactions could lead to the growth of the molecular size and the bottom-up formation of diverse complex molecules (Krasnokutski et al. 2017a,b).

Until recently, no clean source of $\mathrm{C}$ atoms was available (Krasnokutski \& Huisken 2014), and thus only a limited number of reactions of $\mathrm{C}$ atoms has been investigated in the laboratory. Moreover, most studies of these reactions have been performed in the gas phase, and the information about similar surface processes remains limited. As a result, the data about the surface reaction rates, barriers, and products have often been adopted from the gas-phase studies. However, because the third body (a dust grain) enables association reactions, surface reactions with $\mathrm{C}$ atoms might be more efficient than their gas-phase counterparts.

One of the most important reactions involving carbon atoms is the reaction between $\mathrm{C}$ and $\mathrm{H}_{2}$. This reaction is very slow in the gas phase at low temperatures. The radiative association channel leading to the formation of $\mathrm{CH}_{2}$ has a low reaction constant $\sim 10^{-17} \mathrm{~cm}^{3} \mathrm{~s}^{-1}$ (Becker et al. 1989; Dean et al. 1991; Husain \& Young 1975), while the neutral-neutral reaction channel leading to $\mathrm{CH}+\mathrm{H}$ is highly endothermic, with a barrier of $12000 \mathrm{~K}$ (Wakelam et al. 2012).

In contrast, as found by quantum chemical computations, the surface reaction $\mathrm{C}+\mathrm{H}_{2}+\mathrm{M} \rightarrow \mathrm{CH}_{2}+\mathrm{M}$ does not possess any significant energy barrier (Bussery-Honvault et al. 2005; Harding et al. 1993; Lin \& Guo 2004). We recently performed a series of laboratory studies of this reaction. The superfluid helium nanodroplets flying through a vacuum chamber were doped with carbon atoms and dihydrogen molecules. The outcome of the reactions was monitored using mass spectrometry and calorimetric technique. The calorimetry technique allowed us to estimate the amount of energy released in the reactions before the ionization point. The liquid helium acts like a chemically inert dust surface because it absorbs the excess of reaction energy. The reaction $\mathrm{C}+\mathrm{H}_{2}+\mathrm{M} \rightarrow \mathrm{CH}_{2}+\mathrm{M}$ was found to be fast at $T=0.37 \mathrm{~K}$ (Krasnokutski et al. 2016; Henning \& Krasnokutski 2019). This demonstrates the absence of the energy barrier in the surface reaction pathway and ensures a high reaction rate at low temperatures in the ISM.

However, in many gas-grain astrochemical models the surface reaction of $\mathrm{C}$ with $\mathrm{H}_{2}$ is assumed to have a barrier of 2500 K (Garrod \& Herbst 2006; Belloche et al. 2014; Wakelam et al. 2012), including our ALCHEMIC model (Semenov et al. 2010). In this paper, we investigate how strongly the results of astrochemical modelling of the ISM are sensitive to the adopted value of this barrier. In Sect. 2, the adopted physical and chemical model is described. Results and discussion are presented in Sect. 3. The conclusions follow.

\section{Physical and chemical model}

The adopted chemical model is based on the public gas-grain ALCHEMIC code ${ }^{4}$ (see Semenov et al. 2010). The chemical

\footnotetext{
4 http://www.mpia.de/homes/semenov/disk_chemistry_ OSUO8ggs_UV.zip
}

network is based on the osu.2007 ratefile with the recent updates to the reaction rates from the Kinetic Database for Astrochemistry (KIDA; Wakelam et al. 2012) and the high-temperature network of Harada et al. (2010) and Semenov \& Wiebe (2011). The model considers both gas-phase and grain-surface chemistry and consists of 653 atomic and molecular species made of 12 elements, and neutral, negatively, and positively charged grains, which are involved in 7907 reactions.

The standard cosmic ray (CR) ionization rate was assumed, $\zeta_{\mathrm{CR}}=1.3 \times 10^{-17} \mathrm{~s}^{-1}$. The interstellar UV radiation field with the intensity of 1 in the Draine units was used. The self-shielding of $\mathrm{H}_{2}$ from photodissociation was calculated by Eq. (37) from Draine \& Bertoldi (1996). The shielding of CO by dust grains, $\mathrm{H}_{2}$, and the $\mathrm{CO}$ self-shielding was calculated using a precomputed table of Lee et al. (1996, Table 11).

The gas-grain interactions include sticking of neutral species and electrons to dust grains with $100 \%$ probability and desorption of ices by thermal, CRP-, and UV-driven processes. Uniform compact amorphous silicate particles of olivine stoichiometry with a density of $3 \mathrm{~g} \mathrm{~cm}^{-3}$ and a radius of $0.1 \mu \mathrm{m}$ were considered. Each grain provides $1.88 \times 10^{6}$ surface sites for surface recombinations (Biham et al. 2001) through the Langmuir-Hinshelwood mechanism (Hasegawa et al. 1992). A UV photodesorption yield of $10^{-5}$ was adopted (Cruz-Diaz et al. 2016; Bertin et al. 2016). Photodissociation processes of solid species were taken from Garrod \& Herbst (2006) and Semenov $\&$ Wiebe (2011). A $1 \%$ probability for nonthermal chemical desorption was assumed (Garrod et al. 2007; Vasyunin \& Herbst 2013). The ratio between diffusion and desorption barriers for ices was taken to be 0.75 for all ices. The standard rate equation approach to model the surface chemistry was used. As initial abundances, the low metal elemental abundances of Graedel et al. (1982), Lee et al. (1998), and Agúndez \& Wakelam (2013) were adopted, with hydrogen being mainly in a molecular form (see Table 1).

We considered two distinct scenarios in which our chemical network remained almost identical except for the energy barrier of the single $\mathrm{C}+\mathrm{H}_{2} \rightarrow \mathrm{CH}_{2}$ surface reaction. In the first scenario, the original energy barrier $E_{\mathrm{a}}=2500 \mathrm{~K}$ was used (ORG). In the second scenario, we assumed that this reaction has no barrier (MOD). In what follows, for convenience we use the word "ice" when giving the names of the surface species.

Using this chemical model and the two distinct networks, we computed the ISM chemical evolution over $10^{6} \mathrm{yr}$ on a $2 \mathrm{D}$ physical grid with 400 cells. The gas volume densities range between $10^{3}$ and $10^{12} \mathrm{~cm}^{-3}$, and the kinetic temperature varies between 10 and $300 \mathrm{~K}$. We considered dark and partly UV-illuminated ISM conditions with the visual extinction factors of $A_{\mathrm{V}}=20$ and $3 \mathrm{mag}$, respectively. The chemical simulations took about two hours on the Intel Core i7 4-core $2.5 \mathrm{GHz}$ CPU with the ALCHEMIC code compiled with gfortran 6.4.0.

To compare the computed time-dependent abundances between the two chemical networks, we used the abundance ratio $\delta x$ and abundance difference $\Delta x$ as follows:

$\delta x_{i, k}\left(t_{j}\right)=\frac{x_{i, k}^{\mathrm{MOD}}\left(t_{j}\right)}{x_{i, k}^{\mathrm{ORG}}\left(t_{j}\right)}$,

$\Delta x_{i, k}\left(t_{j}\right)=x_{i, k}^{\mathrm{MOD}}\left(t_{j}\right)-x_{i, k}^{\mathrm{ORG}}\left(t_{j}\right)$,

where $x_{i, k}\left(t_{j}\right)$ is the relative abundance of a species $i$ with respect to the total amount of hydrogen nuclei $\left(n_{\mathrm{H}}+2 n_{\mathrm{H}_{2}}\right)$ at a particular time moment $t_{j}$ in the grid cell number $k$ in the original (ORG) and modified (MOD) networks. 
Table 1. Initial abundances in the chemical model.

\begin{tabular}{ll}
\hline \hline Species & Relative abundances \\
\hline $\mathrm{H}_{2}$ & 0.4999 \\
$\mathrm{H}$ & $2.00(-4)$ \\
$\mathrm{He}$ & $1.4(-1)$ \\
$\mathrm{C}^{+}$ & $7.3(-5)$ \\
$\mathrm{N}$ & $2.14(-5)$ \\
$\mathrm{O}$ & $1.76(-4)$ \\
$\mathrm{S}^{+}$ & $2.0(-8)$ \\
$\mathrm{Si}^{+}$ & $3.0(-9)$ \\
$\mathrm{Na}^{+}$ & $3.0(-9)$ \\
$\mathrm{Mg}^{+}$ & $3.0(-9)$ \\
$\mathrm{Fe}^{+}$ & $3.0(-9)$ \\
$\mathrm{P}^{+}$ & $3.0(-9)$ \\
$\mathrm{Cl}^{+}$ & $3.0(-9)$ \\
$\mathrm{e}^{-}$ & $7.3038(-05)$ \\
\hline
\end{tabular}

The abundance ratio $\delta x$ is useful to show the strongest deviations among the considered molecular species, but it can be prone to large jumps in abundances of minor species with low concentrations. To avoid this, we imposed a relative abundance threshold of $10^{-12}$, meaning that if the value of $x_{i, k}^{\mathrm{ORG}}$ or $x_{i, k}^{\mathrm{MOD}}$ was lower than this threshold, their abundance ratio $\delta x$ was forced to be 1 . In contrast, the abundance difference $\Delta x$ is useful to study how elemental atomic carbon is being redistributed among major chemical species by the change in the energy barrier of the $\mathrm{C}+$ $\mathrm{H}_{2}$ surface reaction. Below we use both of these criteria to perform the chemical analysis of the differences between the two chemical networks.

\section{Results}

To facilitate the chemical analysis, we split it into several parts. First, we focus on investigating the overall effect of the barrier change in the single surface reaction on our gas-grain chemical model. For this, we used relative abundance ratios computed for all time moments and the entire 2D physical grid and isolated sets of the most affected species. Next, we restricted our analysis to the time moment $t_{j}=10^{6} \mathrm{yr}$ as a representative timescale for many interstellar environments such as low-mass molecular clouds, and protoplanetary disks.

\subsection{Most affected species at all time moments}

In Table 2 we list the 40 most affected species (with the highest increased or decreased abundances) over the entire $T-n_{\mathrm{H}}$ grid for all computed time moments and for the two visual extinction factors. We recall that the same molecule can fall into both categories of the species with the highest increased or decreased abundances because it depends on physical conditions. The majority of the most affected species for all computed time moments clearly are ices and radicals. Only a few gaseous species appear in Table 2. For the $A_{\mathrm{V}}=3 \mathrm{mag}$ case, these include $\mathrm{C}, \mathrm{CN}, \mathrm{O}_{2}$, and $\mathrm{CH}_{2} \mathrm{OH}$. In the $A_{\mathrm{V}}=20 \mathrm{mag}$ case, only $\mathrm{C}$ appears as a gaseous species in Table 2 . The ice abundances that strongly increase when the surface reaction between $\mathrm{C}$ and $\mathrm{H}_{2}$ becomes rapid include small hydrocarbons (e.g., $\mathrm{CH}_{n}$ $\left.(n=2-4), \mathrm{C}_{2} \mathrm{H}_{4}, \mathrm{C}_{3}\right), \mathrm{HCO}, \mathrm{O}_{2} \mathrm{H}, \mathrm{N}$-bearing ices $\left(\mathrm{NH}_{2}, \mathrm{C}_{3} \mathrm{~N}\right.$, $\mathrm{H}_{2} \mathrm{CN}, \mathrm{HCCN}, \mathrm{OCN}$ ), a few metal and Si-bearing ices, and many organic and complex organic species $\left(\mathrm{CH}_{2} \mathrm{CN}, \mathrm{CH}_{2} \mathrm{OH}\right.$, etc.). The ice abundances that strongly decrease include atomic $\mathrm{C}, \mathrm{H}_{2}$,
Table 2. The 40 species that were most affected by the barrier change for all time moments and the entire 2D physical grid for both visual extinction factors.

\begin{tabular}{|c|c|c|c|}
\hline \multicolumn{2}{|c|}{$A_{\mathrm{V}}=3 \mathrm{mag}$} & \multicolumn{2}{|c|}{$A_{\mathrm{V}}=20 \mathrm{mag}$} \\
\hline Species & $\delta x_{i, k}\left(t_{j}\right)$ & Species & $\delta x_{i, k}\left(t_{j}\right)$ \\
\hline ice $\mathrm{CH}_{2}$ & $3.52 \mathrm{E}+02$ & ice $\mathbf{O}_{2} \mathbf{H}$ & $1.38 \mathrm{E}+05$ \\
\hline ice $\mathrm{CH}_{3}$ & $3.05 \mathrm{E}+02$ & ice $\mathrm{CH}_{2} \mathrm{OH}$ & $7.82 \mathrm{E}+04$ \\
\hline ice $\mathbf{O}_{2} \mathbf{H}$ & $1.25 \mathrm{E}+02$ & ice $\mathrm{CH}_{3} \mathrm{NH}$ & $1.87 \mathrm{E}+04$ \\
\hline ice $\mathrm{CH}_{4}$ & $1.16 \mathrm{E}+02$ & ice $\mathbf{H}_{2} \mathbf{C N}$ & $1.81 \mathrm{E}+04$ \\
\hline ice $\mathrm{CH}_{2} \mathrm{OH}$ & $1.02 \mathrm{E}+02$ & ice $\mathrm{CH}_{2} \mathbf{N H}$ & $1.13 \mathrm{E}+04$ \\
\hline ice $\mathrm{CH}_{2} \mathrm{NH}_{2}$ & $8.29 \mathrm{E}+01$ & ice $\mathbf{C}_{3} \mathbf{O}$ & $3.42 \mathrm{E}+03$ \\
\hline ice $\mathrm{CH}_{3} \mathbf{N H}$ & $8.29 E+01$ & ice $\mathbf{C}_{3} \mathbf{N}$ & $2.99 \mathrm{E}+03$ \\
\hline ice $\mathrm{C}_{2} \mathrm{H}_{4}$ & $8.21 \mathrm{E}+01$ & ice $\mathrm{C}_{3}$ & $2.80 \mathrm{E}+03$ \\
\hline ice $\mathrm{CH}_{2} \mathrm{NH}$ & $8.05 \mathrm{E}+01$ & ice $\mathbf{C}_{2} \mathbf{H}_{5}$ & $2.30 \mathrm{E}+03$ \\
\hline ice $\mathrm{CH}_{2} \mathrm{CN}$ & $6.48 \mathrm{E}+01$ & ice $\mathrm{HCO}$ & $1.75 \mathrm{E}+03$ \\
\hline ice $\mathrm{HCCN}$ & $6.47 \mathrm{E}+01$ & ice $\mathrm{HC}_{3} \mathrm{O}$ & $8.29 E+02$ \\
\hline ice $\mathrm{C}_{2} \mathrm{~N}$ & $6.08 \mathrm{E}+01$ & ice $\mathrm{CH}_{2}$ & $3.52 \mathrm{E}+02$ \\
\hline ice $\mathrm{OCN}$ & $5.83 \mathrm{E}+01$ & ice $\mathrm{CH}_{3}$ & $3.05 \mathrm{E}+02$ \\
\hline ice $\mathrm{HCO}$ & $5.22 \mathrm{E}+01$ & ice $\mathbf{N H}_{2}$ & $2.82 \mathrm{E}+02$ \\
\hline ice $\mathrm{CH}_{3} \mathrm{OH}$ & $5.18 \mathrm{E}+01$ & ice $\mathrm{MgH}$ & $2.50 \mathrm{E}+02$ \\
\hline ice $\mathrm{H}_{2} \mathrm{CN}$ & $3.52 \mathrm{E}+01$ & ice $\mathrm{C}_{2} \mathrm{H}_{3}$ & $2.21 \mathrm{E}+02$ \\
\hline ice $\mathrm{NH}_{2} \mathrm{CHO}$ & $3.00 \mathrm{E}+01$ & ice NH & $1.89 \mathrm{E}+02$ \\
\hline $\mathrm{O}_{2}$ & $2.23 \mathrm{E}+01$ & ice $\mathbf{N a}$ & $1.78 \mathrm{E}+02$ \\
\hline $\mathrm{CH}_{2} \mathrm{OH}$ & $2.04 \mathrm{E}+01$ & ice $\mathrm{SiH}_{2}$ & $1.63 \mathrm{E}+02$ \\
\hline ice $\mathrm{C}_{2}$ & $1.84 \mathrm{E}+01$ & ice $\mathbf{F e}$ & $1.63 \mathrm{E}+02$ \\
\hline ice $\mathrm{C}$ & $1.59 \mathrm{E}-07$ & & $5.22 \mathrm{E}-08$ \\
\hline ice $\mathrm{C}_{3} \mathrm{H}_{3}$ & $1.65 \mathrm{E}-04$ & ice $\mathbf{H}_{2}$ & 4.19E-05 \\
\hline ice $\mathrm{C}_{3} \mathrm{H}_{4}$ & $4.29 \mathrm{E}-04$ & ice $\mathrm{O}_{2} \mathbf{H}$ & $9.81 \mathrm{E}-05$ \\
\hline $\mathrm{C}$ & $6.39 \mathrm{E}-04$ & ice $\mathrm{C}_{3} \mathrm{H}_{4}$ & $1.49 \mathrm{E}-04$ \\
\hline ice $\mathrm{H}_{2}$ & $6.79 \mathrm{E}-04$ & ice $\mathrm{CH}_{2} \mathbf{N H}$ & $1.66 \mathrm{E}-04$ \\
\hline ice $\mathbf{C}_{2} \mathbf{O}$ & $9.77 \mathrm{E}-04$ & ice $\mathrm{C}_{3} \mathrm{H}_{3}$ & $2.11 \mathrm{E}-04$ \\
\hline ice $\mathrm{HCCN}$ & $1.02 \mathrm{E}-03$ & ice HCO & 2.19E-04 \\
\hline ice $\mathrm{C}_{2} \mathrm{H}_{3}$ & $1.05 \mathrm{E}-03$ & $\mathrm{C}$ & $3.05 \mathrm{E}-04$ \\
\hline ice $\mathrm{HC}_{2} \mathrm{O}$ & $1.13 \mathrm{E}-03$ & ice $\mathbf{C}_{2} \mathbf{H}_{3}$ & $3.99 \mathrm{E}-04$ \\
\hline ice $\mathrm{C}_{2} \mathrm{H}$ & $1.26 \mathrm{E}-03$ & ice $\mathrm{CH}_{2} \mathrm{OH}$ & $4.38 \mathrm{E}-04$ \\
\hline ice $\mathrm{C}_{2}$ & $1.55 \mathrm{E}-03$ & ice $\mathrm{C}_{2}$ & $6.13 \mathrm{E}-04$ \\
\hline ice $\mathrm{C}_{2} \mathrm{~N}$ & $1.91 \mathrm{E}-03$ & ice $\mathrm{HCCN}$ & $6.81 \mathrm{E}-04$ \\
\hline ice $\mathrm{C}_{6} \mathrm{H}$ & $2.14 \mathrm{E}-03$ & ice $\mathrm{CH}_{2} \mathrm{CN}$ & $8.00 \mathrm{E}-04$ \\
\hline ice $\mathrm{C}_{5} \mathrm{H}$ & $2.58 \mathrm{E}-03$ & ice $\mathrm{HC}_{2} \mathrm{O}$ & $8.90 \mathrm{E}-04$ \\
\hline ice $\mathrm{C}_{6}$ & $3.31 \mathrm{E}-03$ & ice $\mathrm{C}_{2} \mathrm{O}$ & $8.96 \mathrm{E}-04$ \\
\hline ice $\mathrm{C}_{6} \mathrm{H}_{2}$ & $3.32 \mathrm{E}-03$ & ice $\mathrm{C}_{2} \mathrm{H}$ & $1.24 \mathrm{E}-03$ \\
\hline ice $\mathrm{CH}$ & $3.37 \mathrm{E}-03$ & ice $\mathrm{C}_{6} \mathrm{H}$ & $1.30 \mathrm{E}-03$ \\
\hline ice $\mathrm{CH}_{2} \mathrm{CN}$ & 4.77E-03 & ice $\mathbf{C}_{3}$ & $1.56 \mathrm{E}-03$ \\
\hline ice $\mathrm{C}_{5} \mathrm{H}_{2}$ & $5.54 \mathrm{E}-03$ & ice $\mathrm{C}_{5} \mathrm{H}$ & $1.76 \mathrm{E}-03$ \\
\hline $\mathrm{CN}$ & $6.21 \mathrm{E}-03$ & ice $\mathrm{C}_{2} \mathrm{~N}$ & $1.83 \mathrm{E}-03$ \\
\hline
\end{tabular}

Notes. Species whose abundance changes are caused by rapid transitions to another chemical state are listed in boldface (see explanation in text).

larger hydrocarbons (up to six $\mathrm{C}$ atoms), $\mathrm{O}_{2} \mathrm{H}, \mathrm{HCO}, \mathrm{HC}_{2} \mathrm{O}$, $\mathrm{N}$-bearing ices $\left(\mathrm{C}_{2} \mathrm{~N}, \mathrm{HCCN}\right)$, and a smaller number of COMs. The degree of abundance increase or decrease is much higher in the UV-dark $A_{\mathrm{V}}=20 \mathrm{mag}$ case, where the role of surface chemistry is stronger.

We used the abundance ratio $\delta x(i)$ to construct this table. These values are prone to wide variations for the species whose chemical evolution undergoes a rapid transition to another chemical state, for instance, as a result of freeze-out. This includes transient minor species such as Si- and metal-bearing ices. For 

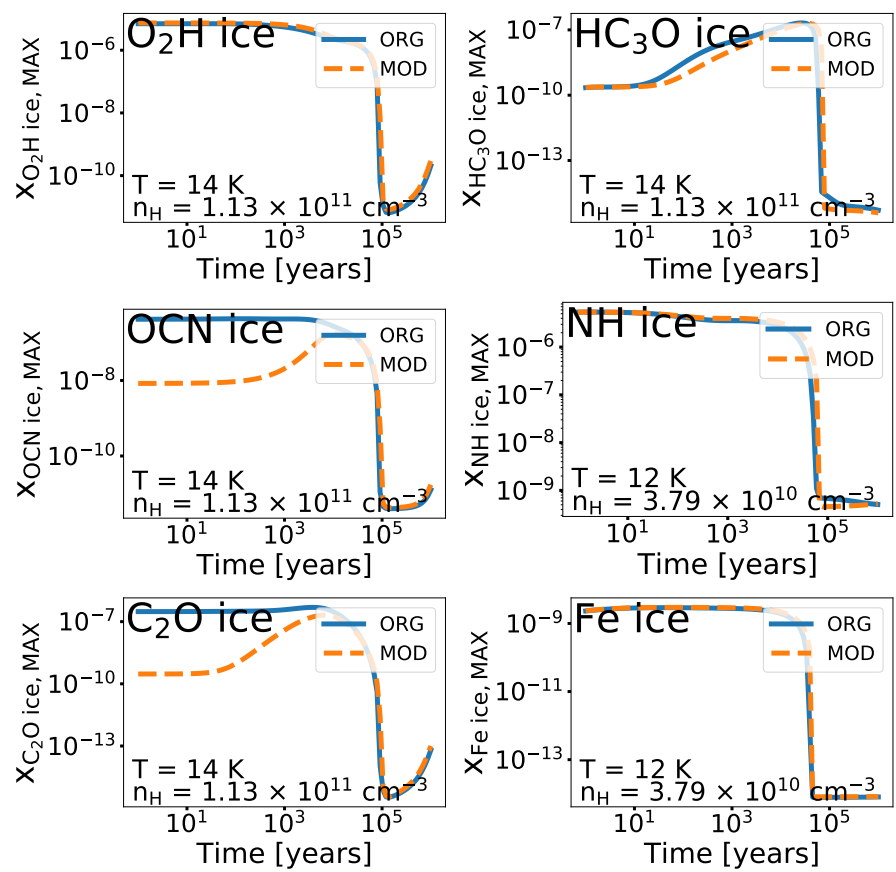

Fig. 1. Time-dependent abundances of some surface species from Table 2 at physical conditions where the difference between both chemical models is most significant. The partly UV-irradiated model with $A_{\mathrm{V}}=3 \mathrm{mag}$ is shown at the left, and the "dark" model with $A_{\mathrm{V}}=20$ mag at the right.

example, for the $\mathrm{O}_{2} \mathrm{H}, \mathrm{HC}_{3} \mathrm{O}, \mathrm{NH}$, and Fe ices in Fig. 1, there is a slight shift in the time moment when their abundance drops rapidly at $\sim 10^{5} \mathrm{yr}$, causing large abundance variations. However, the overall shape of their time-dependent abundances remains very similar in the original and modified chemical models. The chemical evolution for other species may start differently, as it does for OCN and $\mathrm{C}_{2} \mathrm{O}$ ices in Fig. 1, although large changes are still attributed to the same factor.

The other most affected species include those that are chemically closely related to the $\mathrm{C}$ and $\mathrm{CH}_{2}$ ices. This is expected because the surface reaction $\mathrm{C}+\mathrm{H}_{2} \rightarrow \mathrm{CH}_{2}$ is at the root of their chemical evolution. The higher efficiency of this single reaction without the barrier leads to a lower concentration of $\mathrm{C}$ atoms on the dust surfaces and to more efficient production of $\mathrm{CH}_{n}$ ices by surface hydrogenation. Because there is less surface atomic carbon available for other reactions, carbon insertion surface reactions leading to $C_{n}(n \geq 2)$ and related species become less effective and the abundances of these polyatomic carbon species decrease in general.

However, the abundances of some $\mathrm{C}_{2}$ and $\mathrm{C}_{3}$-bearing species do increase in the modified chemical model, for instance, $\mathrm{C}_{2} \mathrm{H}_{4}$ ice, $\mathrm{C}_{2} \mathrm{~N}$ ice, $\mathrm{C}_{2}$ and $\mathrm{HCCN}$ ices $\left(A_{\mathrm{V}}=3 \mathrm{mag}\right.$ case $)$, and $\mathrm{C}_{2} \mathrm{H}_{3}$ ice, $\mathrm{HC}_{3} \mathrm{O}$ ice, $\mathrm{C}_{3} \mathrm{O}$ ice, $\mathrm{C}_{3} \mathrm{~N}, \mathrm{C}_{2} \mathrm{H}_{5}$, and $\mathrm{C}_{3}\left(A_{\mathrm{V}}=20\right.$ mag case $)$. This is related to more efficient surface reactions involving $\mathrm{CH}_{2}$ and $\mathrm{CH}_{3}$ radicals in the modified model, for example, $\mathrm{CH}_{2}+$ $\mathrm{CH}_{2} \rightarrow \mathrm{C}_{2} \mathrm{H}_{4}$ and $\mathrm{CH}_{2}+\mathrm{CH}_{3} \rightarrow \mathrm{C}_{2} \mathrm{H}_{5}$. Further reactions of these hydrocarbon ices with $\mathrm{O}$ - or $\mathrm{N}$-bearing species and photoprocessing by UV lead to the synthesis of polycarbonaceous $\mathrm{N}$ and O-bearing ices.

\subsection{Most affected species at $t_{j}=10^{6} \mathrm{yr}$}

Because many low-mass prestellar and star-forming environments have a typical evolutionary timescale of about $1 \mathrm{Myr}$, we
Table 3. The 40 species that were most affected by the barrier change for the final time moment $\left(t_{j}=10^{6} \mathrm{yr}\right)$ and the entire 2D physical grid for the two visual extinction factors.

\begin{tabular}{|c|c|c|c|}
\hline \multicolumn{2}{|c|}{$A_{\mathrm{V}}=3 \mathrm{mag}$} & \multicolumn{2}{|c|}{$A_{\mathrm{V}}=20 \mathrm{mag}$} \\
\hline Species & $\delta x_{i, k}\left(10^{6} \mathrm{yr}\right)$ & Species & $\delta x_{i, k}\left(10^{6} \mathrm{yr}\right)$ \\
\hline $\mathrm{C}_{2} \mathrm{H}_{4}$ & $1.09 \mathrm{E}+01$ & ice $\mathrm{HCO}$ & $1.48 \mathrm{E}+01$ \\
\hline ice $\mathrm{CH}_{2}$ & $8.01 \mathrm{E}+00$ & ice $\mathrm{NH}_{2} \mathrm{CHO}$ & $1.47 \mathrm{E}+01$ \\
\hline ice $\mathrm{CH}_{2} \mathrm{OH}$ & 7.99E+00 & ice $\mathrm{CH}_{3} \mathrm{OCH}_{3}$ & $1.31 \mathrm{E}+01$ \\
\hline ice $\mathrm{CH}_{3}$ & $7.93 \mathrm{E}+00$ & ice $\mathrm{C}_{2} \mathrm{H}_{5} \mathrm{OH}$ & $1.31 \mathrm{E}+01$ \\
\hline ice $\mathrm{CH}_{3} \mathrm{OH}$ & $7.90 \mathrm{E}+00$ & ice $\mathrm{CH}_{3} \mathrm{OH}$ & $1.30 \mathrm{E}+01$ \\
\hline ice $\mathrm{CH}_{4}$ & $7.60 \mathrm{E}+00$ & ice $\mathrm{C}_{2} \mathrm{H}_{6}$ & $1.21 \mathrm{E}+01$ \\
\hline ice $\mathrm{H}_{2} \mathrm{CO}$ & $7.02 \mathrm{E}+00$ & ice $\mathrm{CH}_{2} \mathrm{NH}$ & $7.42 \mathrm{E}+00$ \\
\hline ice $\mathrm{C}_{2} \mathrm{H}_{4}$ & $5.24 \mathrm{E}+00$ & ice $\mathrm{CH}_{3} \mathrm{NH}$ & $7.42 \mathrm{E}+00$ \\
\hline $\mathrm{CH}_{2}$ & $4.38 \mathrm{E}+00$ & ice $\mathrm{CH}_{5} \mathrm{~N}$ & $7.22 \mathrm{E}+00$ \\
\hline $\mathrm{CH}_{4}$ & $4.15 \mathrm{E}+00$ & ice OCN & $5.47 \mathrm{E}+00$ \\
\hline ice $\mathrm{NH}_{2} \mathrm{CHO}$ & $3.97 \mathrm{E}+00$ & $\mathrm{H}_{2} \mathrm{CO}$ & $5.09 \mathrm{E}+00$ \\
\hline $\mathrm{C}_{2} \mathrm{H}_{2}$ & $3.46 \mathrm{E}+00$ & ice $\mathrm{O}_{3}$ & $4.74 \mathrm{E}+00$ \\
\hline $\mathrm{CH}_{3}$ & $3.39 \mathrm{E}+00$ & $\mathrm{C}_{2} \mathrm{H}_{4}$ & $4.70 \mathrm{E}+00$ \\
\hline $\mathrm{H}_{2} \mathrm{CO}$ & $3.38 \mathrm{E}+00$ & $\mathrm{O}_{2}$ & $4.60 \mathrm{E}+00$ \\
\hline $\mathrm{C}_{2} \mathrm{H}$ & $3.18 \mathrm{E}+00$ & ice $\mathrm{O}_{2}$ & $3.92 \mathrm{E}+00$ \\
\hline ice $\mathrm{O}_{3}$ & $2.90 \mathrm{E}+00$ & NO & $3.63 \mathrm{E}+00$ \\
\hline ice $\mathrm{H}_{2} \mathrm{CN}$ & $2.83 \mathrm{E}+00$ & $\mathrm{CH}_{4}$ & $3.35 \mathrm{E}+00$ \\
\hline $\mathrm{CH}$ & $2.70 \mathrm{E}+00$ & $\mathrm{NH}$ & $3.30 \mathrm{E}+00$ \\
\hline ice $\mathrm{CH}_{2} \mathrm{NH}$ & $2.69 \mathrm{E}+00$ & ice $\mathrm{CH}_{3} \mathrm{C}_{3} \mathrm{~N}$ & $3.25 \mathrm{E}+00$ \\
\hline ice $\mathrm{CH}_{3} \mathrm{NH}$ & $2.59 \mathrm{E}+00$ & $\mathrm{OCN}$ & $3.23 \mathrm{E}+00$ \\
\hline ice $\mathrm{C}_{5} \mathrm{H}_{2}$ & $1.42 \mathrm{E}-02$ & ice $\mathrm{C}_{3} \mathrm{H}_{4}$ & $3.21 \mathrm{E}-04$ \\
\hline ice $\mathrm{C}_{6} \mathrm{H}_{2}$ & $3.43 \mathrm{E}-02$ & ice $\mathrm{C}_{6} \mathrm{H}_{2}$ & $3.28 \mathrm{E}-03$ \\
\hline ice $\mathrm{C}_{6} \mathrm{H}$ & $4.25 \mathrm{E}-02$ & ice $\mathrm{CH}_{3} \mathrm{CN}$ & 4.71E-03 \\
\hline ice $\mathrm{C}_{7} \mathrm{H}_{2}$ & $4.48 \mathrm{E}-02$ & ice $\mathrm{C}_{5} \mathrm{H}_{2}$ & $6.20 \mathrm{E}-03$ \\
\hline ice $\mathrm{C}$ & $1.32 \mathrm{E}-01$ & ice HNCO & $1.37 \mathrm{E}-02$ \\
\hline ice $\mathrm{CH}_{3} \mathrm{CN}$ & $1.38 \mathrm{E}-01$ & ice $\mathrm{CH}_{2} \mathrm{CO}$ & $1.41 \mathrm{E}-02$ \\
\hline $\mathrm{C}$ & $1.44 \mathrm{E}-01$ & ice $\mathrm{C}_{4} \mathrm{H}_{4}$ & $2.59 \mathrm{E}-02$ \\
\hline ice $\mathrm{C}_{2} \mathrm{H}_{4}$ & $1.46 \mathrm{E}-01$ & ice $\mathrm{C}_{4} \mathrm{H}_{2}$ & $2.70 \mathrm{E}-02$ \\
\hline $\mathrm{HCCN}$ & $1.60 \mathrm{E}-01$ & ice $\mathrm{C}_{4} \mathrm{H}_{3}$ & $3.14 \mathrm{E}-02$ \\
\hline ice $\mathrm{CH}_{2} \mathrm{CN}$ & $1.67 \mathrm{E}-01$ & ice $\mathrm{C}_{7} \mathrm{H}_{2}$ & $3.18 \mathrm{E}-02$ \\
\hline ice $\mathrm{CS}$ & $1.68 \mathrm{E}-01$ & ice $\mathrm{C}_{4} \mathrm{H}$ & $3.18 \mathrm{E}-02$ \\
\hline ice $\mathrm{HCCN}$ & $1.72 \mathrm{E}-01$ & ice $\mathrm{CH}_{2} \mathrm{CN}$ & 4.42E-02 \\
\hline ice $\mathrm{C}_{2} \mathrm{~N}$ & $1.75 \mathrm{E}-01$ & ice $\mathrm{C}_{2} \mathrm{H}_{4}$ & $5.34 \mathrm{E}-02$ \\
\hline ice $\mathrm{C}_{2} \mathrm{H}_{2}$ & $1.88 \mathrm{E}-01$ & ice $\mathrm{HNC}_{3}$ & $6.84 \mathrm{E}-02$ \\
\hline ice $\mathrm{C}_{2} \mathrm{H}_{3}$ & $1.96 \mathrm{E}-01$ & ice $\mathrm{HC}_{5} \mathrm{~N}$ & $7.55 \mathrm{E}-02$ \\
\hline ice $\mathrm{C}_{4} \mathrm{H}_{2}$ & $1.98 \mathrm{E}-01$ & ice $\mathrm{C}_{4} \mathrm{~N}$ & $9.01 \mathrm{E}-02$ \\
\hline $\mathrm{C}_{2} \mathrm{H}$ & 2.13E-01 & ice HNC & $1.22 \mathrm{E}-01$ \\
\hline ice $\mathrm{C}_{2} \mathrm{O}$ & 2.14E-01 & ice $\mathrm{H}_{2} \mathrm{CS}$ & $1.31 \mathrm{E}-01$ \\
\hline $\mathrm{C}_{2} \mathrm{H}_{2}$ & 2.22E-01 & ice $\mathrm{C}$ & $2.00 \mathrm{E}-01$ \\
\hline ice $\mathrm{HC}_{2} \mathrm{O}$ & 2.23E-01 & ice $\mathrm{HCCN}$ & $3.47 \mathrm{E}-01$ \\
\hline
\end{tabular}

list in Table 3 the 40 species for which the abundance changes are the largest at the final evolutionary time moment in our simulations $\left(t_{j}=10^{6} \mathrm{yr}\right)$. By that time, many species that are produced mainly by gas-phase reactions attain a chemical quasi-steadystate, and the corresponding abundance ratios $\delta x_{i}$ are therefore much lower than in Table 2. In contrast, complex organic species that are solely synthesized by slow surface processes do not reach steady state by $t=1$ Myr. Table 3 contains many (complex) organic species, including $\mathrm{H}_{2} \mathrm{CO}, \mathrm{HNCO}, \mathrm{CH}_{3} \mathrm{OH}, \mathrm{CH}_{2} \mathrm{CN}$, and $\mathrm{CH}_{3} \mathrm{OCH}_{3}$. The majority of species in Table 3 are still hydrocarbon and N-bearing carbonaceous ices, as in Table 2. The exotic metals, Si-bearing ices, and other transient radicals such as $\mathrm{O}_{2} \mathrm{H}$ are no longer present because strong variations in their 

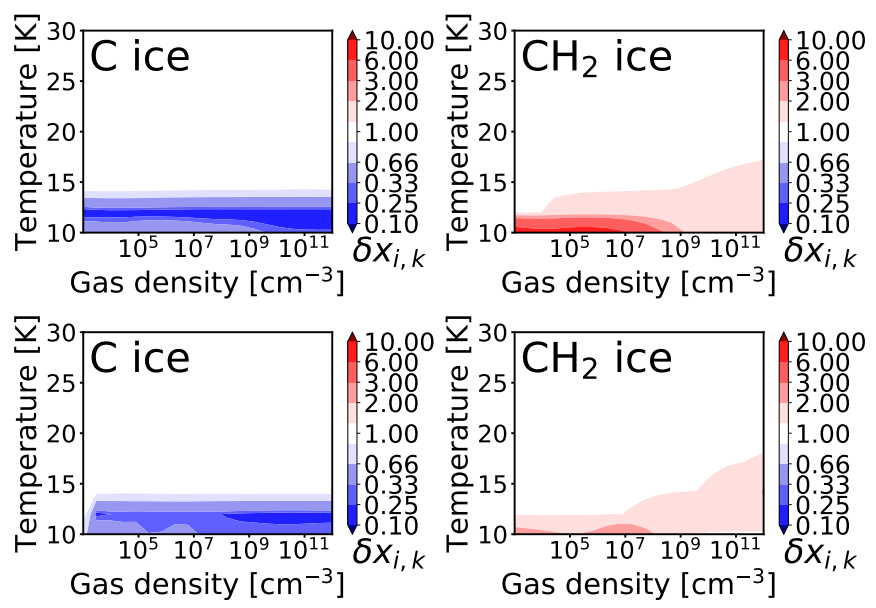

Fig. 2. Abundance ratios $\delta x$ for the surface $\mathrm{C}$ and $\mathrm{CH}_{2}$ as a function of density and temperature at $t_{j}=10^{6} \mathrm{yr}$. The partly UV-irradiated model with $A_{\mathrm{V}}=3$ mag is shown at the top, and the dark model with $A_{\mathrm{V}}=$ 20 mag at the bottom.
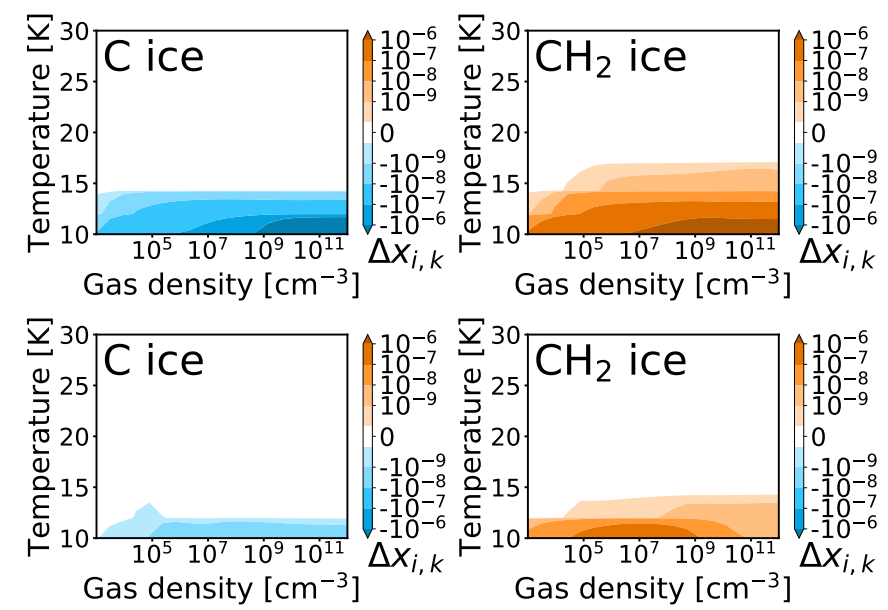

Fig. 3. Abundance difference $\Delta x$ for the surface $\mathrm{C}$ and $\mathrm{CH}_{2}$ molecules as a function of density and temperature at $t_{j}=10^{6} \mathrm{yr}$. The partly UVirradiated model with $A_{\mathrm{V}}=3 \mathrm{mag}$ is shown at the top, and the dark model with $A_{\mathrm{V}}=20$ mag at the bottom.

abundances mainly occur during the build-up phase of the ice mantles. Moreover, there are more gaseous species in the list of the most affected species at $1 \mathrm{Myr}$, such as $\mathrm{C}$, small hydrocarbons, $\mathrm{O}_{2}, \mathrm{H}_{2} \mathrm{CO}, \mathrm{NO}, \mathrm{NH}$, and $\mathrm{OCN}$. Most of these simple gaseous species have been detected in the diffuse and dense ISM.

Next, we aim to better understand how late-time chemistry of key molecules is affected by the barrier change in the $\mathrm{C}+$ $\mathrm{H}_{2}$ surface reaction. While we computed our grid for a wide range of temperatures, we found that most of the abundance variations occur at low temperatures of $\lesssim 10-30 \mathrm{~K}$, when most of the volatiles are frozen and where surface reactions are most active. We therefore limit the analysis to this temperature range below.

The abundance ratios and differences for the $\mathrm{C}$ and $\mathrm{CH}_{2}$ ices and their time-dependent abundances in a representative grid cell with $n_{\mathrm{H}}=3.79 \times 10^{10} \mathrm{~cm}^{-3}$ and $T=12 \mathrm{~K}$ are shown in Figs. 2-4. Figures 2 and 3 clearly show that the surface abundances of $\mathrm{C}$ atoms decrease by a factor of $\sim 2-5$, while those of the surface $\mathrm{CH}_{2}$ increase by a factor of $\gtrsim 2-6$ when the $\mathrm{C}+\mathrm{H}_{2}$ surface reaction proceeds without a barrier. The abundance variations for both species occur at $T \lesssim 14-16 \mathrm{~K}$, and for the entire density range, they lie between $10^{3}$ and $10^{12} \mathrm{~cm}^{-3}$. Interestingly,
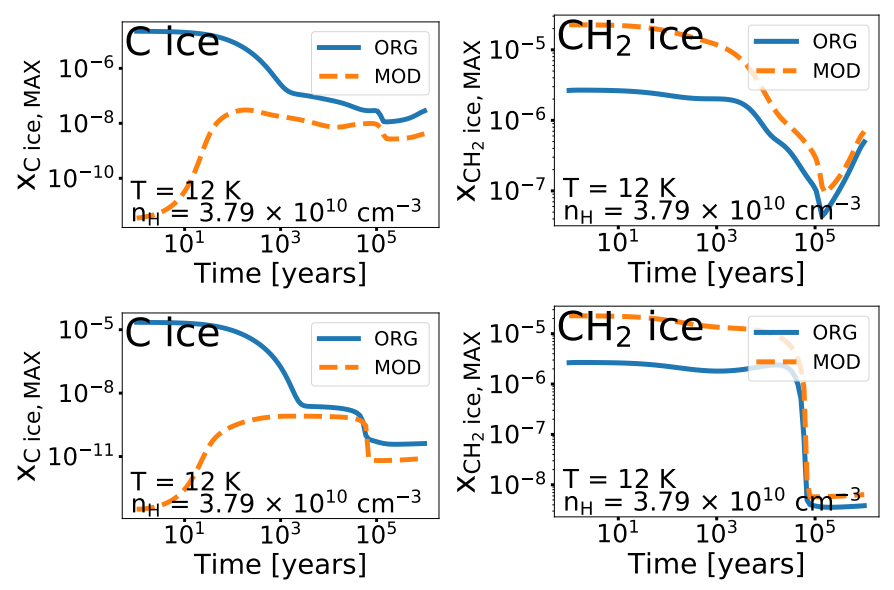

Fig. 4. Time-dependent abundances of surface species $\mathrm{C}$ and $\mathrm{CH}_{2}$ at physical conditions where the difference between the two chemical models is most significant. The partly UV-irradiated model with $A_{\mathrm{V}}=$ $3 \mathrm{mag}$ is shown at the top, and the dark model with $A_{\mathrm{V}}=20 \mathrm{mag}$ at the bottom.

the model with more interstellar UV photons shows stronger variations than the UV-dark model. Enhanced local UV radiation constantly liberates atomic carbon from $\mathrm{C}$-bearing species, making the effect of the barrierless $\mathrm{C}+\mathrm{H}_{2}$ surface reaction on species abundances stronger (Fig. 3).

The abundance ratios of $\mathrm{C}$ and $\mathrm{CH}_{2}$ ices in the two models tend to be anticorrelated. In the UV-illuminated case, the abundance ratios for the $\mathrm{CH}_{2}$ ice become negligible at higher densities, $n_{\mathrm{H}} \gtrsim 10^{8} \mathrm{~cm}^{-3}$ compared to the $\mathrm{C}$ ice. At these high densities, the relative abundances of $\mathrm{CH}_{2}$ ice become higher than those of the $\mathrm{C}$ ice and hence are less prone to abundance variations. Abundance ratios for both $\mathrm{C}$ and $\mathrm{CH}_{2}$ ices are much lower in the UV-dark case, where most of the volatiles are depleted and surface chemistry converts a substantial fraction of $\mathrm{C}$ into complex organic ices, lowering the role of the $\mathrm{C}+\mathrm{H}_{2}$ reaction and the $\mathrm{C}$ and $\mathrm{H}_{2}$ ice abundances at $1 \mathrm{Myr}$.

Time-dependent abundances relative to the total amount of hydrogen nuclei for $\mathrm{C}$ and $\mathrm{CH}_{2}$ ices are shown in Fig. 4. At the chosen physical conditions $T=12 \mathrm{~K}, n_{\mathrm{H}}=3.79 \times 10^{10} \mathrm{~cm}^{-3}$, the abundance changes are significant for most of the species in the chemical model. These physical conditions are representative of the densest regions of low-mass starless cores and protoplanetary disk mid-planes. The freeze-out timescale onto $0.1 \mu \mathrm{m}$ grains at this density is only a few years.

The abundance variations between the two chemical models for both $\mathrm{C}$ and $\mathrm{CH}_{2}$ ices are initially very high, $\sim 5-8$ and $\sim 1$ orders of magnitude, respectively, and decrease with time. The relative abundances of the $\mathrm{C}$ ice are lower in the modified model with the fast $\mathrm{C}+\mathrm{H}_{2}$ reaction. In contrast, the abundances of the $\mathrm{CH}_{2}$ ice are higher in the modified model. The pace of abundance convergence between the two models for the $\mathrm{C}$ ice is rapid until $\sim 1-3 \times 10^{3} \mathrm{yr}$, and becomes slower after that. For the $\mathrm{CH}_{2}$ ice the pace of the abundance convergence is slower than for the $\mathrm{C}$ ice. Both $\mathrm{C}$ and $\mathrm{CH}_{2}$ ices experience a transition to another chemical state at $\sim 10^{5} \mathrm{yr}$, where their abundance further decreases. These two timescales, $\sim 1-3 \times 10^{3}$ and $\sim 10^{5} \mathrm{yr}$, correspond to the final conversion of $\mathrm{O}$ ice into $\mathrm{OH}$ ice and $\mathrm{OH}$ ice into water ice, respectively. After this, more surface hydrogen atoms and molecules become available for competitive reactions, for instance, involving $\mathrm{C}$ and hydrocarbon ices. In the end, the elemental carbon is reshuffled mainly into methane and $\mathrm{CO}$ ices, with the addition of the COM ices. 

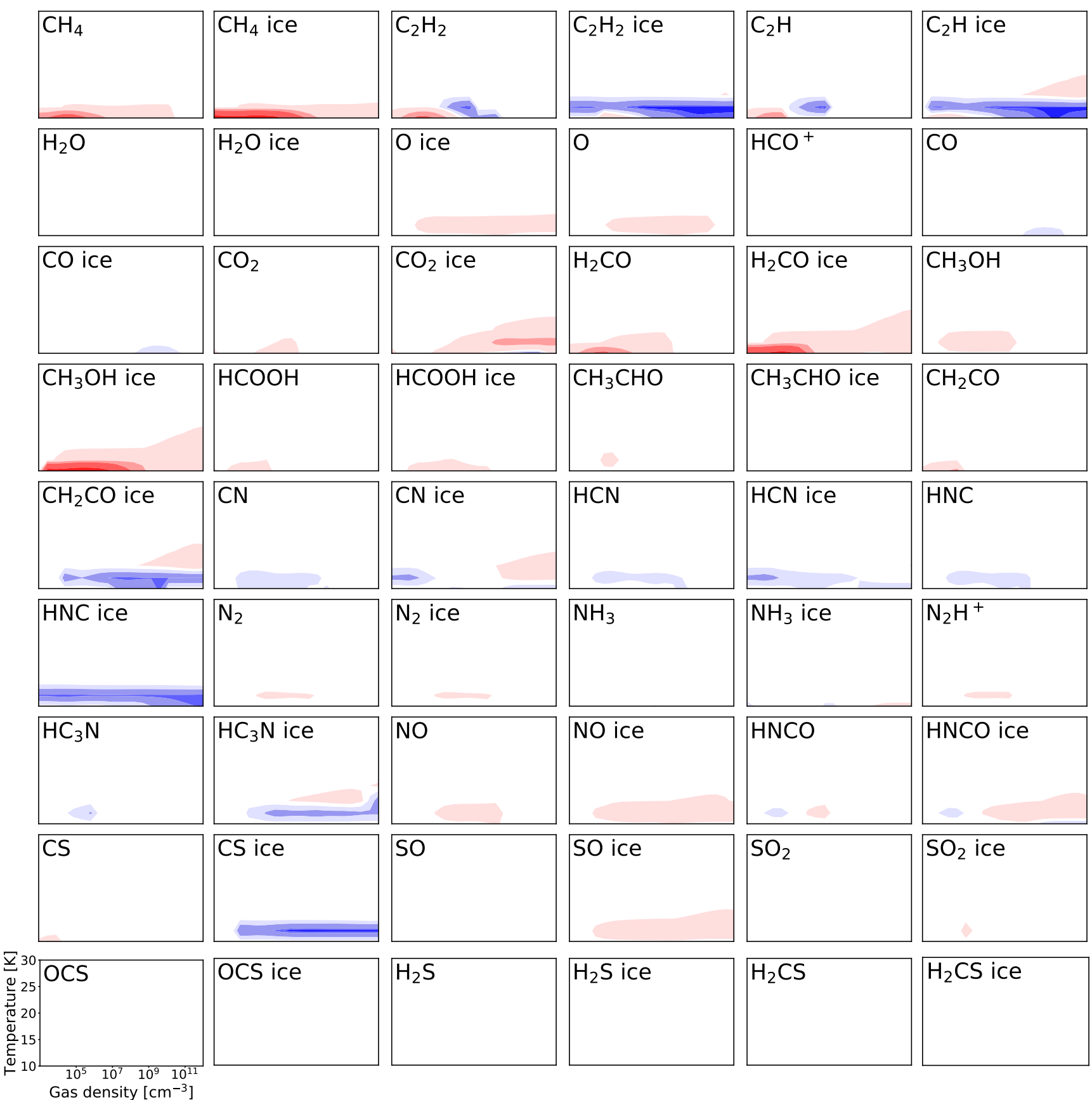

Fig. 5. Abundance ratios $\delta x$ between the modified and original networks are shown for the entire 2D physical grid at $t_{j}=10^{6}$ yr for selected observed species. The results are depicted for the $A_{\mathrm{V}}=3$ mag case.

To place these findings into a more general context, we show similar abundance ratio plots for a range of selected gaseous species observed in the ISM and their ices for the two models with different $A_{\mathrm{V}}$ in Figs. 5 and 6. Highly abundant $\mathrm{CO}$, $\mathrm{H}_{2} \mathrm{O}$, and $\mathrm{N}_{2}$ as well as other simple species such as $\mathrm{O}, \mathrm{HCO}^{+}$, $\mathrm{N}_{2} \mathrm{H}^{+}, \mathrm{NH}_{3}$, NO and most of $\mathrm{S}$-bearing molecules clearly remain relatively unaffected by the surface $\mathrm{C}+\mathrm{H}_{2}$ barrier change. In contrast, abundances of $\mathrm{CO}_{2}$ ice, $\mathrm{H}_{2} \mathrm{CO}, \mathrm{CN}, \mathrm{HCN}, \mathrm{HNC}, \mathrm{CS}$, $\mathrm{H}_{2} \mathrm{CS}$, hydrocarbons, and organic molecules such as $\mathrm{H}_{2} \mathrm{CO}$, $\mathrm{CH}_{3} \mathrm{OH}$, and $\mathrm{HNCO}$ (either gas and/or ice) vary by more than a factor of two between the original and modified chemical models.

The abundances of key species, $\mathrm{CO}, \mathrm{H}_{2} \mathrm{O}$, and $\mathrm{N}_{2}$, do change between the original and modified chemical models, but these deviations are small compared to their relative abundances. For instance, the relative abundance differences for the $\mathrm{CO}$ ice in the original and modified chemical models are not negligible, $\sim 10^{-6}-10^{-5}$, but these values are at least several times lower than the total $\mathrm{CO}$ relative abundance $\gtrsim 5 \times 10^{-5}$. This leads to a small difference in the $\mathrm{CO}$ relative abundance ratios in both models. The relative abundance differences for the $\mathrm{CO}$ ice between the original and modified chemical models are $\Delta x(\mathrm{CO}) \lesssim 10^{-6}-10^{-5}$, while its relative abundances $x(\mathrm{CO})$ at $1 \mathrm{Myr}$ are at least a few times $10^{-5}$.

In Figs. 5 and 6 , the rise in abundance of $\mathrm{CH}_{4}$ at low temperatures $\lesssim 15 \mathrm{~K}$ in the modified model is related to more efficient surface hydrogenation of $\mathrm{CH}_{2} \cdot \mathrm{CH}_{2}$ is rapidly produced through the $\mathrm{C}+\mathrm{H}_{2}$ surface reaction when it has no barrier. The 

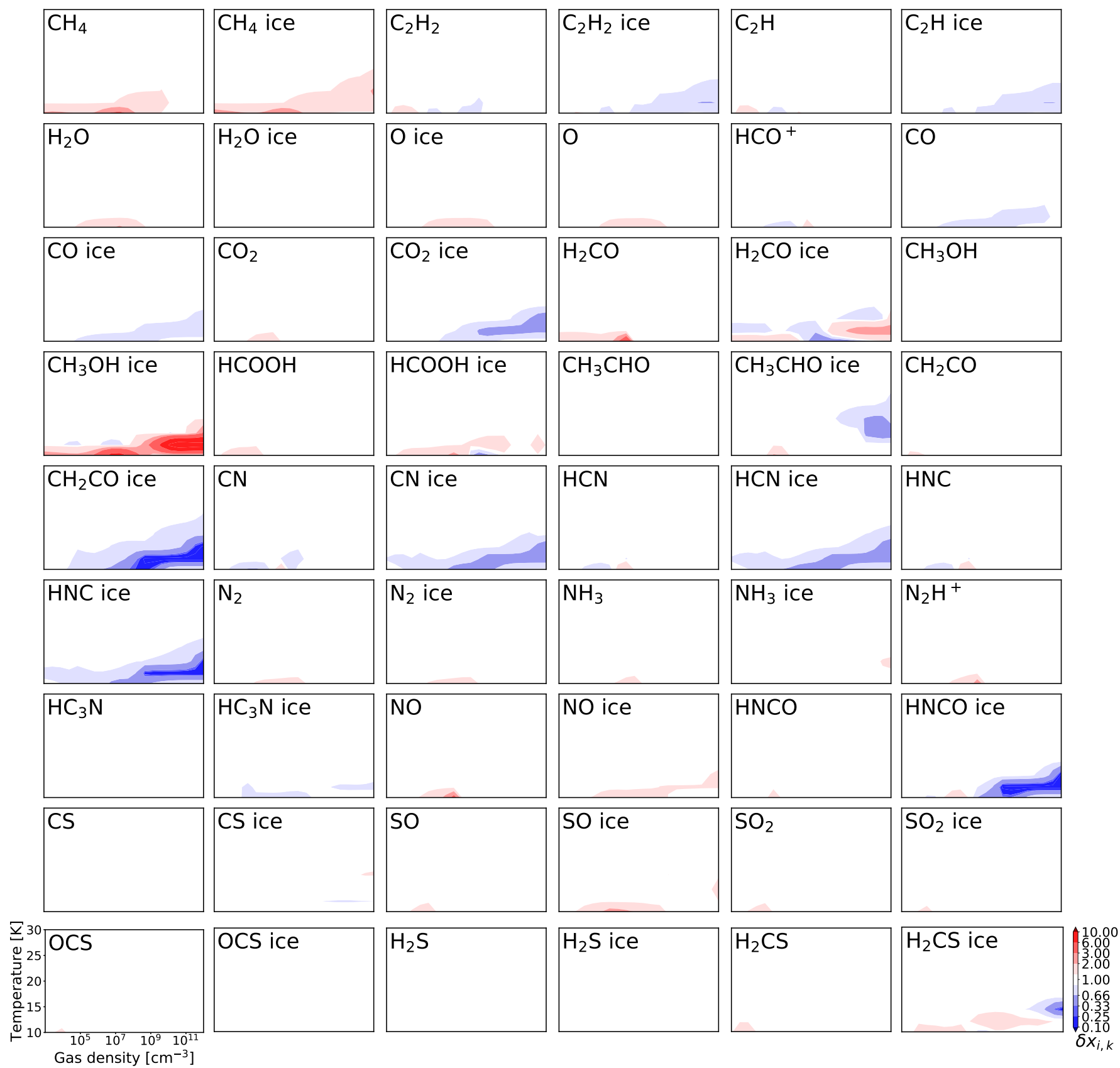

Fig. 6. Same as Fig. 5, but for the $A_{\mathrm{V}}=20$ mag case.

abundances of larger hydrocarbons with two or more $\mathrm{C}$ atoms in general decrease as a result of competition, as more reactive carbon becomes locked in methane ice. This also affects the abundances of $\mathrm{CN}, \mathrm{HCN}$, and $\mathrm{HNC}$ (gas/ice) as well as CS and $\mathrm{H}_{2}$ ice in a similar manner because their formation pathways directly involve light hydrocarbons.

The abundances of simple organic molecules such as $\mathrm{H}_{2} \mathrm{CO}$ and $\mathrm{CH}_{3} \mathrm{OH}$ mostly increase in the modified model. This is due to a similar mechanism of water ice formation that we discussed before for the evolution of $\mathrm{C}$ and $\mathrm{CH}_{2}$ ices. The increase in surface $\mathrm{H}$ at late times allows more surface $\mathrm{CO}$ to become hydrogenated and thus more $\mathrm{H}_{2} \mathrm{CO}$ and $\mathrm{CH}_{3} \mathrm{OH}$ ices can be synthesized. In the modified model $\mathrm{CH}_{4}$ is formed as a consequence of surface hydrogenation of mono-carbonic ices as well as by our evaluated reaction. The increase in the efficiency of the latter keeps some of the atomic $\mathrm{H}$ free to form organic molecules.
The abundances of the $\mathrm{CH}_{2} \mathrm{CO}$ ice decreases in the modified chemical model due to the competition between formation of the $\mathrm{CH}_{n}$ and $\mathrm{C}_{2} \mathrm{H}_{m}$ ices. $\mathrm{CH}_{2} \mathrm{CO}$ ice in our chemical network mainly forms from the $\mathrm{C}_{2}$-bearing ices. A similar abundance change occurs with the $\mathrm{HNCO}$ and $\mathrm{HC}_{3} \mathrm{~N}$ ices, whose formation is related to the chemistry of nitriles.

\section{Discussion}

\subsection{Reactivity of carbon atoms on dust grain surfaces: missing processes from chemical networks}

One of the main results of this study is that the high reactivity of atomic carbon when the surface reaction $\mathrm{C}+\mathrm{H}_{2}$ is barrierless increases abundances of complex organic ices. This influence might be particularly important during the early stages 
of molecular cloud formation, when the $\mathrm{CII} \rightarrow \mathrm{CI} \rightarrow \mathrm{CO}$ conversion is not yet completed. In our modeling, the initial form of carbon in the ISM is expected to be CII. During formation of molecular clouds, the atomic carbon undergoes a series of chemical transformations in the gas phase, leading to the formation of $\mathrm{CO}$. If the cloud cools to low, $\$ 30 \mathrm{~K}$ temperatures, $\mathrm{C}$ atoms will start to accrete onto dust surfaces, where more complex species may form, including COMs.

Despite the importance of the surface chemistry involving atomic carbon, contemporary chemical databases do not include many of these reactions. Our chemical network and the KIDA database contains only about 35 surface reactions involving $\mathrm{C}$ atoms. Most of these reactions are related to the growth of the carbon chains $\mathrm{C}_{n} \mathrm{X}+\mathrm{C} \rightarrow \mathrm{C}_{n+1} \mathrm{X}$, where $\mathrm{X}$ could be $\mathrm{H}, \mathrm{O}$, $\mathrm{N}, \mathrm{S}$, or none. This is in strong contrast to numerous laboratory studies that demonstrated that $\mathrm{C}$ atoms can react without a barrier with almost all species present in the ice mantles (Chastaing et al. 2000, 2001; Kaiser \& Mebel 2002; Kaiser et al. 1999; Krasnokutski et al. 2017a, 2019, 2020; Shannon et al. 2014; Henning \& Krasnokutski 2019; Hickson et al. 2016).

For example, the reaction $\mathrm{C}+\mathrm{NH}_{3} \rightarrow \mathrm{CH}_{2} \mathrm{NH}$ has recently been found to be barrierless and therefore is expected to be important for the formation of glycine and other amino acids and COM ices (Krasnokutski et al. 2020). Furthermore, the product of this reaction, $\mathrm{CH}_{2} \mathrm{NH}$, is formed in a long-living excited state, allowing it to participate in other chemical reactions with considerable energy barriers. The low-temperature reaction $\mathrm{C}+$ $\mathrm{H}_{2} \mathrm{O} \rightarrow \mathrm{H}_{2} \mathrm{CO}$ is expected to proceed fast on the ice surfaces due to quantum tunnelling (Hickson et al. 2016). It might therefore be expected that by extending a set of surface reactions with atomic carbon in modern chemical networks, complexity and predicted abundances of the COM ices increase.

\subsection{TMC1 benchmark}

The question arises whether the theoretical chemical modeling we presented might be applied to real astronomical objects and whether the adopted chemical model and networks are feasible. To test the feasibility of the original and modified chemical models, we compared computed and observed abundances in the prototypical TMC1 molecular cloud. We used the observed relative abundances from Agúndez \& Wakelam (2013), as well as their initial abundances and OD physical conditions: uniform gas and dust temperature $T=10 \mathrm{~K}, n_{\mathrm{H}}=2 \times 10^{4} \mathrm{~cm}^{-3}$, $A_{\mathrm{V}}=10 \mathrm{mag}$, a dust-to-gas-mass ratio of 0.01 , and a grain radius of $0.1 \mu \mathrm{m}$. The agreement $a_{i}$ between the modeled and observed abundances was calculated for each of the observed species as follows:

$a_{i}= \begin{cases}1 ; & 0.1 \leq x_{i}\left(t_{j}\right) / x_{i, \mathrm{obs}} \leq 10 \\ 0 ; & \text { otherwise, }\end{cases}$

where $x_{i}\left(t_{j}\right)$ is the modeled relative abundance of a species $i$ at a particular time moment $\left(t_{j}\right)$ for the original (ORG) or modified (MOD) model, and $x_{i, \mathrm{obs}}$ is the relative observed abundance (with respect to the amount of molecular hydrogen). The agreement values $a_{i}$ were summed over all observed species.

The percentage of the species reproduced by the two chemical models plotted as a function of time is shown in Fig. 7. Both models clearly show the best agreement of about $60 \%$ at a late time, $\sim 10^{5} \mathrm{yr}$, similar to what was found by Agúndez et al. (2008) and other previous studies. There is no significant difference between the two chemical models because the observed species in TMC1 are mainly simple gas-phase species, not that

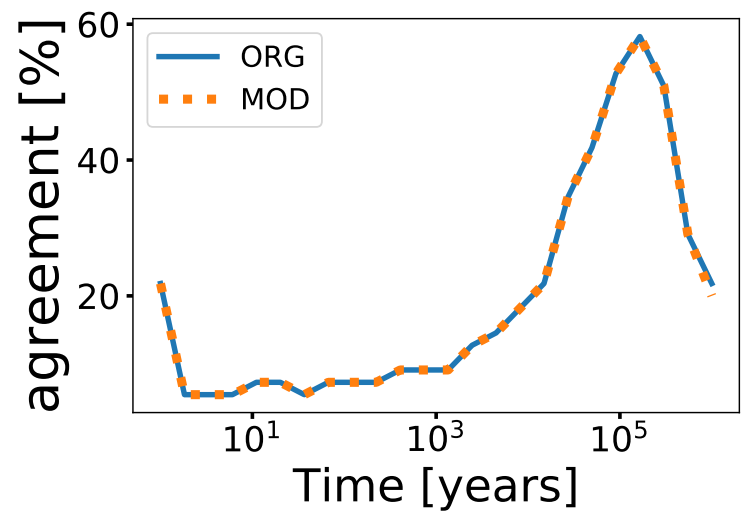

Fig. 7. Percentage of the observed species in the TMC1 cloud reproduced by our two chemical models as a function of time.

many hydrocarbons that are sensitive to the barrier change in the surface $\mathrm{C}+\mathrm{H}_{2}$ reaction were detected there.

Other environments were the effect of the barrier change in the surface reaction between $\mathrm{C}$ and $\mathrm{H}_{2}$ on the chemical composition could be more pronounced are protoplanetary disks with their cold outer mid-plane regions and warmer molecular layers. However, for the sake of brevity, we leave this investigation for another paper.

\section{Conclusion}

We performed a thorough theoretical study of the effect of the barrier change in the single surface reaction $\mathrm{C}+\mathrm{H}_{2} \rightarrow \mathrm{CH}_{2}$ on the time-dependent chemical evolution in a wide range of physical conditions typical for the interstellar medium. We found that the most affected species are hydrocarbon ices and their gas-phase counterparts. The absence of the barrier in the $\mathrm{C}+$ $\mathrm{H}_{2}$ reaction leads to a faster conversion of the surface carbon atoms into methane ice. More efficient synthesis of monocarbonic hydrocarbon ices $\left(\mathrm{CH}_{2}, \mathrm{CH}_{3}\right.$, and $\left.\mathrm{CH}_{4}\right)$ lowers the efficiency of formation for larger hydrocarbons, cyanides, and nitriles, and CS-bearing species at low temperatures $\lesssim 10-30 \mathrm{~K}$. The absence of the barrier in the $\mathrm{C}+\mathrm{H}_{2}$ reaction increases the efficiency of the surface hydrogenation of $\mathrm{CO}$ and hence the synthesis of complex organic ices. However, abundances of major species such as $\mathrm{CO}, \mathrm{H}_{2} \mathrm{O}$, and $\mathrm{N}_{2}$ as well as $\mathrm{O}, \mathrm{HCO}^{+}$, $\mathrm{N}_{2} \mathrm{H}^{+}, \mathrm{NH}_{3}$, NO, and most of the $\mathrm{S}$-bearing molecules remain almost unaffected. These global chemical trends are similar in the UV-irradiated $\left(A_{\mathrm{V}}=3 \mathrm{mag}\right)$ and UV-dark environments $\left(A_{\mathrm{V}}=20 \mathrm{mag}\right)$. The effect of the $\mathrm{C}+\mathrm{H}_{2}$ surface reaction barrier value on the gas-phase chemistry is limited by the low efficiency of the desorption mechanism in our molecular cloud model. In contrast, in less UV-dark astrophysical environments, this higher desorption would produce a larger effect on the gas-phase abundances.

We conclude that the fast reactivity of atomic carbon on dust grain surfaces, which has recently been measured in laboratory experiments and confirmed by quantum chemical calculations, is of considerable importance for contemporary astrochemical models. These processes, which are currently not fully included in public astrochemical databases such as KIDA, need to be taken into account to better understand the chemical cycle of carbon and the synthesis of hydrocarbon and organic ices in the ISM. Further laboratory measurements and/or quantum chemical computations are required to determine other important surface reactions with carbon atoms. 
Acknowledgements. D.S. acknowledges support by the Deutsche Forschungsgemeinschaft through SPP 1833: "Building a Habitable Earth" (SE 1962/6-1). S.K. is grateful for the support by the Max Planck Institute for Astronomy and the Deutsche Forschungsgemeinschaft DFG (grants No. KR 3995/4-

1). M.S. is thankful for the support from the Erasmus+ Programme and the Slovenian Research Agency (ARRS) through research core fundings No. P1-0201. T.H. acknowledges support from the European Research Council under the Horizon 2020 Framework Program via the ERC Advanced Grant "Origins" 832428

\section{References}

Agúndez, M., \& Wakelam, V. 2013, Chem. Rev., 113, 8710

Agúndez, M., Cernicharo, J., \& Goicoechea, J. R. 2008, A\&A, 483, 831

Becker, K. H., Engelhardt, B., Wiesen, P., \& Bayes, K. D. 1989, Chem. Phys. Lett., 154, 342

Belloche, A., Garrod, R. T., Müller, H. S. P., \& Menten, K. M. 2014, Science, 345,1584

Bertin, M., Romanzin, C., Doronin, M., et al. 2016, ApJ, 817, L12

Biham, O., Furman, I., Pirronello, V., \& Vidali, G. 2001, ApJ, 553, 595

Bussery-Honvault, B., Julien, J., Honvault, P., \& Launay, J. M. 2005, Phys. Chem. Chem. Phys., 7, 1476

Chastaing, D., Le Picard, S. D., \& Sims, I. R. 2000, J. Chem. Physi., 112, 8466

Chastaing, D., Le Picard, S. D., Sims, I. R., \& Smith, I. W. M. 2001, A\&A, 365, 241

Cruz-Diaz, G. A., Martín-Doménech, R., Muñoz Caro, G. M., \& Chen, Y.-J. 2016, A\&A, 592, A68

Cuppen, H. M., Walsh, C., Lamberts, T., et al. 2017, Space Sci. Rev., 212,

Dean, A. J., Davidson, D. F., \& Hanson, R. K. 1991, J. Phys. Chem., 95, 183

Draine, B. T., \& Bertoldi, F. 1996, ApJ, 468, 269

Garrod, R. T., \& Herbst, E. 2006, A\&A, 457, 927

Garrod, R. T., Wakelam, V., \& Herbst, E. 2007, A\&A, 467, 1103

Graedel, T. E., Langer, W. D., \& Frerking, M. A. 1982, ApJS, 48, 32
Harada, N., Herbst, E., \& Wakelam, V. 2010, ApJ, 721, 1570

Harding, L. B., Guadagnini, R., \& Schatz, G. C. 1993, J. Phys. Chem., 97, 5472

Hasegawa, T. I., Herbst, E., \& Leung, C. M. 1992, ApJS, 82, 167

Henning, T. K., \& Krasnokutski, S. A. 2019, Nat. Astron., 3, 568

Henning, T., \& Semenov, D. 2013, Chem. Rev., 113, 9016

Herbst, E., \& van Dishoeck, E. F. 2009, ARA\&A, 47, 427

Herbst, E., \& Yates, J. T. 2013, Chem. Rev., 113, 8707

Hickson, K. M., Loison, J. C., Nunez-Reyes, D., \& Mereau, R. 2016, J. Phys. Chem. Lett., 7, 3641

Hollenbach, D., \& Salpeter, E. E. 1971, ApJ, 163, 155

Husain, D., \& Young, A. N. 1975, J. Chem. Soc., Faraday Trans. 2, 71, 525

Kaiser, R. I., \& Mebel, A. M. 2002, Int. Rev. Phys. Chem., 21, 307

Kaiser, R. I., Mebel, A. M., Chang, A. H. H., Lin, S. H., \& Lee, Y. T. 1999, J. Chem. Phys., 110, 10330

Krasnokutski, S. A., \& Huisken, F. 2014, Appl. Phys. Lett., 105, 113506

Krasnokutski, S. A., Kuhn, M., Renzler, M., et al. 2016, ApJ, 818, L31

Krasnokutski, S. A., Huisken, F., Jäger, C., \& Henning, T. 2017a, ApJ, 836, 32

Krasnokutski, S. A., Goulart, M., Gordon, E. B., et al. 2017b, ApJ, 847, 89

Krasnokutski, S. A., Tkachenko, O., C., J., \& Th, H. 2019, Phys. Chem. Phys. Chem., 21, 12986

Krasnokutski, S. A., Jäger, C., \& Henning, T. 2020, ApJ, 889, 67

Lee, H.-H., Herbst, E., Pineau des Forêts, G., Roueff, E., \& Le Bourlot, J. 1996, A\&A, 311, 690

Lee, H.-H., Roueff, E., Pineau des Forets, G., et al. 1998, A\&A, 334, 1047

Lin, S. Y., \& Guo, H. 2004, J. Phys. Chem. A, 108, 10066

McGuire, B. A. 2018, ApJS, 239, 17

Rimmer, P. B., \& Helling, C. 2016, ApJS, 224, 9

Semenov, D., \& Wiebe, D. 2011, ApJS, 196, 25

Semenov, D., Hersant, F., Wakelam, V., et al. 2010, A\&A, 522, A42

Shannon, R. J., Cossou, C., Loison, J. C., et al. 2014, Rsc Adv., 4, 26342

Tielens, A. G. G. M. 2010, The Physics and Chemistry of the Interstellar Medium (Cambridge: Cambridge University Press)

Vasyunin, A. I., \& Herbst, E. 2013, ApJ, 769, 34

Wakelam, V., Herbst, E., Loison, J.-C., et al. 2012, ApJS, 199, 21 